\title{
Adolescent mothers' non-utilisation of antenatal care services in Bulawayo, Zimbabwe
}

CN Chaibva, D Litt et Phil.

Graduate, Department of Health Studies, UNISA and Lecturer Department of Health Sciences, Zimbabwe Open University, Bulawayo

JH Roos, D Litt et Phil

Associate Professor, Department of Health Studies, UNISA

VJ Ehlers, D Litt et Phil

Professor, Department of Health Studies, UNISA

\section{Key words}

adolescent mother, antenatal care, Health Belief Model, midwifery in Zimbabwe

\section{Correspondence address}

Prof Valerie JEhlers, POBOx 65075, ERASMUSRAND.

Pretoria., 0165. South Africa.

Tel/fax: (012) 347-8287 (home);

Tel: (012) 429-6731/6296 (work)

Fax: (012) 429-6688 marked FOR ATTEN-

TION PROF VJEHLERS.

E-mail: ehlersjh@mweb.co.za (home)

ehlervj@unisa.ac.za

\begin{abstract}
Curationis 32 (3): 14-21
Adolescent pregnancies are high risk obstetric occurrences. Antenatal care (ANC) provides opportunities to recognise and treat obstetric complications, enhancing the pregnancy outcomes for mothers and babies. The purpose of the study was to identify factors influencing adolescents' non-utilisation of ANC services in Bulawayo. The Health Belief Model (HBM) was used to contextualise the study.

A quantitative, non-experimental, descriptive research design was adopted, using structured interviews to collect data. Purposive, non-probability sampling was used to conduct structured interviews with 80 adolescent mothers from the postnatal wards who had delivered their babies without attending ANC.

Factors influencing these adolescent mothers' non-utilisation of ANC services included socio-economic issues, individuals' perceptions about ANC, limited knowledge about $A N C$, policies and structural barriers. However, these adolescents knew' that delivering their babies with skilled attendance could enhance the outcomes for the mothers and babies, would help secure documents to facilitate the acquisition of their children's birth certificates, and that obstetric complications required the services of skilled midwives/doctors. Policy-related issues, such as requiring national identity cards from pregnant adolescents (or from their spouses) prohibited some of them from utilising ANC services.

There is a need to improve adolescents' reproductive health outreach (including $A N C)$ programmes and to offer free ANC services in Zimbabwe. Restrictive policies, such as the required identity cards of the pregnant adolescents (or their husbands), impacted negatively on the accessibility of ANC services and should be addressed as a matter of urgency in Bulawayo.
\end{abstract}




\section{Introduction and background information}

Adolescents' pregnancies and childbirth episodes are major public health challenges worldwide, especially in sub-Saharan Africa (Ebeigbe \& Gharoro, 2007:79). Maternal deaths are five percent higher for females younger than 16 years than for females in their twenties (Mlangeni, 2003 in Grobler. Botha, Jacobs \& Nel, 2007:32). The effective utilisation of antenatal care (ANC) services by adolescents could reduce pregnancy and childbirth complications, and improve the outcomes for mothers and babies.

Adolescents' non-utilisation of ANC services poses threats to the health of the mother and the baby and is associated with poor birth outcomes (Leslie, Findlay, Frappier, Goldberg, Pinzon, Sankaran \& Taddeo, 2006:243). Obstetric complications are high among adolescents who deliver their babies without attending ANC (Loto, Ezechi, Kalu, Loto, Ezechi \& Ogunnivi 2004:398). The status of these adolescents is referred to as "unbooked" in Zimbabwe. Studies conducted by Matua (2004:33) as well as by Omolola, Babatunde, Babalola and Victoria (2004:25) confirmed that pregnancy and childbirth pose particular health risks especially when adolescents fail to utilise $A N C$ services.

Zimbabwe 's maternal mortality rate was reported to be 555 maternal deaths per 100000 live births during 2005/2006 (MOHCW, 2007:11). Zimbabwe accepted the Millennium Development Goals (MDGs), and MDG number five endeavours to improve maternal health and reduce maternal mortalities by $75 \%$ between 2000 and 2015 , by enhancing access to $A N C$ and maternal health services (MOHCW, 2007). Zimbabwe's goal-oriented ANC protocol $M O H C W$. 2000) specifies what activities should be performed by midwives during each trimester of pregnancy. This ANC protocol recommends that every pregnant woman should have six ANC visits if it is an uncomplicated pregnancy. The examinations that should be done include blood pressure, unrinalysis, history taking, abdominal palpations, fundus-symphysis pubis measurements, and voluntary counselling and testing for Human Immune Deficiency Virus
(HIV). Iron supplements, folic acid, tetanus toxoid vaccinations and anti-malaria drugs are supplied to pregnant women, if necessary. If the pregnant woman is HIV positive, the prevention of mother-to-child transmission services must be recommended to her.

Maternal health statistics in Bulawayo for 2004 and 2005 indicate that $22.6 \%$ of the adolescent mothers delivered their babies without attending $A N C$ (MOHCW, 2005:1). Most of these unbooked mothers delivered their babies with the assistance of traditional birth attendants, but some delivered their babies in hospitals when they anticipated or experienced obstetric problems. No policies were implemented in Zimbabwe to trace unbooked mothers and/or those who delivered their babies at home. Mugweni, Ehlers and Roos (2008:11) reported that some Zimbabwean women preferred home deliveries because they disliked any interventions during the delivery of their babies and/or placentas. These authors also indicated that Zimbabwean women, even those with high levels of education, were unaware of the potential dangers of home deliveries especially for primigravidas.

Adolescents' non-utilisation of ANC services may be influenced by health care providers' attitudes as well as by the nature of these services. Aretakis (2004:818) cites barriers, especially among African adolescent mothers, related to non-utilisation of $A N C$, as adolescents dislike providers' care and providers' perceived offensive attitudes tow'ards adolescents.

\section{Conceptual framework}

The research is based on the Health Belief Model (HBM) comprising the following concepts:

- Perceived susceptibility - one's belief about the possibility that one can acquire a condition (or suffer negative consequences by not using ANC services

- $\quad$ Perceived severity - one's belief about the seriousness of the condition (or the potential severity of the consequences for the adolescent mother and/or her baby of not using ANC services)

- $\quad$ Perceived benefits - one's be- lief in the value of actions to prevent the condition (implying the value of using ANC services to optimise the potential outcomes for the mother and the baby)

- $\quad$ Perceived barriers - one's belief in the "cost" to take the prescribed action/s (in this case it implies the perceived barriers to accessing ANC services such as paying for $A N C$ services and for transport to the ANC clinics; the requirement to produce a Zimbabwean identity document of oneselfor one's spouse prior to registering for $A N C$ services; the intention of preg. nant adolescents to hide their pregnancies from their parents and schools until they are in labour; fear of being tested HIV positive)

- $\quad$ Cues to action - strategies to activate and sustain spectfic actions (factors motivating pregnant adolescents to start and continue using ANC services throughout their pregnancies)

- $\quad$ Self-efficacy - one's confidence in one's ability to take action (to attend ANC clinics regularly) Actions taken to avoid the negative consequences of any condition or consequence resulting from the lack of taking a specific action, comprise the key element in the HBM (RECAPP, 2005). The utilisation of $A N C$ sevices to enhance the pregnancy outcomes for both mothers and babies constitutes the key element in the application of the HBM to this study.

\section{Problem statement}

During 2004/5. Zimbabwe's Minister of Health and Child Welfare (MOHCW) was concerned about the $22.6 \%$ adolescent mothers who delivered without any ANC attendance (MOHCW 2005:1), and the $49.0 \%$ who commenced using ANC services only after 28 weeks' gestation, as these practices might contribute to the maternal mortalities in Bulawayo. The MOHCW's report (2005:1) indicated that 63 maternal deaths had been reported in Bulawayo during 2004/5 and that almost $50 \%$ of these deaths occurred among adolescents. 
The first author noticed that some unbooked adolescent mothers delivered their babies in hospital when anticipating or experiencing obstetric problems. Some of these obstetric problems could have been addressed during ANC visits, or identified and referred timeously for more specialised management reducing the risks for mothers and babies.

The problem was that some adolescent mothers failed to use ANC services, despite the availability of these services in Bulawayo, and that it was unknown what factors influenced these adolescent mothers' decisions.

\section{Purpose}

The purpose of the study, on which this article is based, was to identify factors contributing to the non-utilisation of ANC services as perceived by adolescent mothers and to develop strategies to enhance adolescents' effective utilisation of ANC services, ensuring timely management of identified potential risk factors and the possible prevention of complications for both mothers and babies.

The research question that needed to be answered was thus: "Why do adolescent mothers in Bulawayo fail to use the available ANC senices?"

\section{Definitions of concepts}

For the purpose of the study on which the article is based, the following terms have been defined as:

Adolescent mothers: Women aged 19 years or younger, irrespective of gravida, parity, neonatal outcomes or marital status (Ehlers, Maja, Sellers \& Gololo, 2000:46).

Antenatal care: "regular care and monitoring given to a woman during pregnancy" (Mosby Nurses' Pocket Dictionary, 2005:24).

Non-utilisation of ANC: Pregnant adolescents who failed to make use of available ANC services.

\section{Reseach method}

A quantitative, descriptive design was used to identify and quantify factors influencing adolescents' non-utilisation of $A N C$ services.

\section{Sample and sampling methods}

The sample was selected from the accessible population of adolescents in Bulawayo who had delivered their babies in government primary health care (PHC) clinics and hospitals without attending ANC. All the government institutions providing delivery services (four PHC clinics and two hospitals) in Bulawayo comprised the study sites for collecting data. Consequently the population of sites were included in the survey and no sampling of sites took place. Purposive sampling of adolescent mothers was employed, recruiting ten adolescent mothers from each of the two less busy clinics $(10 \times 2=20)$ and 15 mothers $(15 \times 2=30)$ from the two busier clinics and $(15 \times 2=30)$ from the two hospitals. The total sample comprised 80 adolescent mothers.

Non-probability purposive sampling was used to select adolescent mothers who met the following inclusion critenia.

- $\quad$ aged 19 or younger

- delivered their babies without attending $A N C$ regardless of parity and mode of delivery

- $\quad$ delivered their babies at one of the participating clinics or hospitals during May and June 2007

- consented to being inter viewed, and if younger than 18 years of age, their parents/ guardians also had to give consent

- $\quad$ were willing to be interviewed in the post natal ward after being discharged before going home, implying that they would be interviewed after they had received all the required post natal treatments and health information and that they had obtained some rest after delivering their babies.

\section{The research instrument}

A structured interview schedule was used to collect data because it allowed the clarification of unclear statements and unfamiliar terms while also enabling interviewers to identify respondents who might be physically and/or emotionally unable to respond to questions, and avoid interviewing these mothers. As the respondents failed to attend ANC clinics, the researchers anticipated that they might have been unfamiliar with some terms used in the questionnaire; and might have been unable to read and write to the level required for the successful completion of questionnaires.

All respondents opted to use English during the interviews, although the interview schedule was also available in the Ndebele language, and the interviewers could speak Ndebele and English fluently.

The first section of the structured interview schedule aimed to obtain information about adolescent mothers' biographic data (age, marital and educational status, religion, employment and source of income) and the second section addressed obstetric aspects (parity, gravida, obstetric history). The subsequent sections of the interview schedule addressed issues relevant to the HBM's major concepts such as socio-cultural and economic factors influencing their $A N C$ utilisation. knowledge about $A N C$, perceived benefits of and barriers to using ANC services. The last section asked for suggestions to improve ANC services for adolescents.

\section{Validity of the interview schedule}

Validity of the structured interview schedule was enhanced because:

- Questions were in line with the $H B M$ 's major tenets and with the literature review.

- $\quad$ Three midwifery tutors, three senior midwifery practitioners, two promoters and a statistician examined each item 's appropriateness in terms of content and criterion-related validity.

- $\quad$ The structured interview schedule was pre-tested on five postpartum adolescents who did not participate in the actual study, resulting in no changes.

- $\quad$ An independent researcher also evaluated the face and criterion-related validity of the structured interview schedule.

\section{Reliability of the structured interview schedule}

The reliability of the structured interview schedule was enhanced by pre- 
testing it on five adolescent mothers who met the selection criteria and yielded similar results to those of the actual interviews, indicating consistency and stability. The pre-test interviews were conducted by the first author and two research assistants. The information obtained by the three interviewers was compared and yielded similar results, amounting to inter-rater reliability.

\section{Ethical considerations}

Permission was sought from and granted by the heads of the participating health centres and the Medical Research Council of Zimbabwe, and from the Research and Ethics Committee of the Department of Health Studies, Unisa. Informed consent was obtained from the respondents (and their guardians for those under 18 years). Respondents were assured about the confidentiality and anonymity of the information. The purpose and benefits of the study, as well as issues of confidentiality, voluntary participation, privacy and anonymity were discussed prior to each interview.

Adolescents (and their guardians for those younger than 18) were asked to sign a consent form and drop it into a box provided in the postnatal ward (prior to each interview) to ensure anonymity during the interview. In this way no anonymously completed interview' schedule could be linked to any signed consent form. The completed interview schedules were kept in a separate container to which only the researchers and the statistician had access.

\section{Data collection and analysis}

Adolescent mothers were interviewed in the postnatal wards before discharge. They were only interviewed once they had recovered from the labour process and were no longer unduly tired. As the interviews requested information ahout the adolescents personal reasons for not attending $A N C$, no potentially emotionally traumatic questions were asked. Data gathered were coded and analysed using the Statistical Package for Social Sciences (SPSS) version 10.0 computer programme and presented in tables, bar and pie charts.

Figure 1: Age of the respondents $(n=80)$

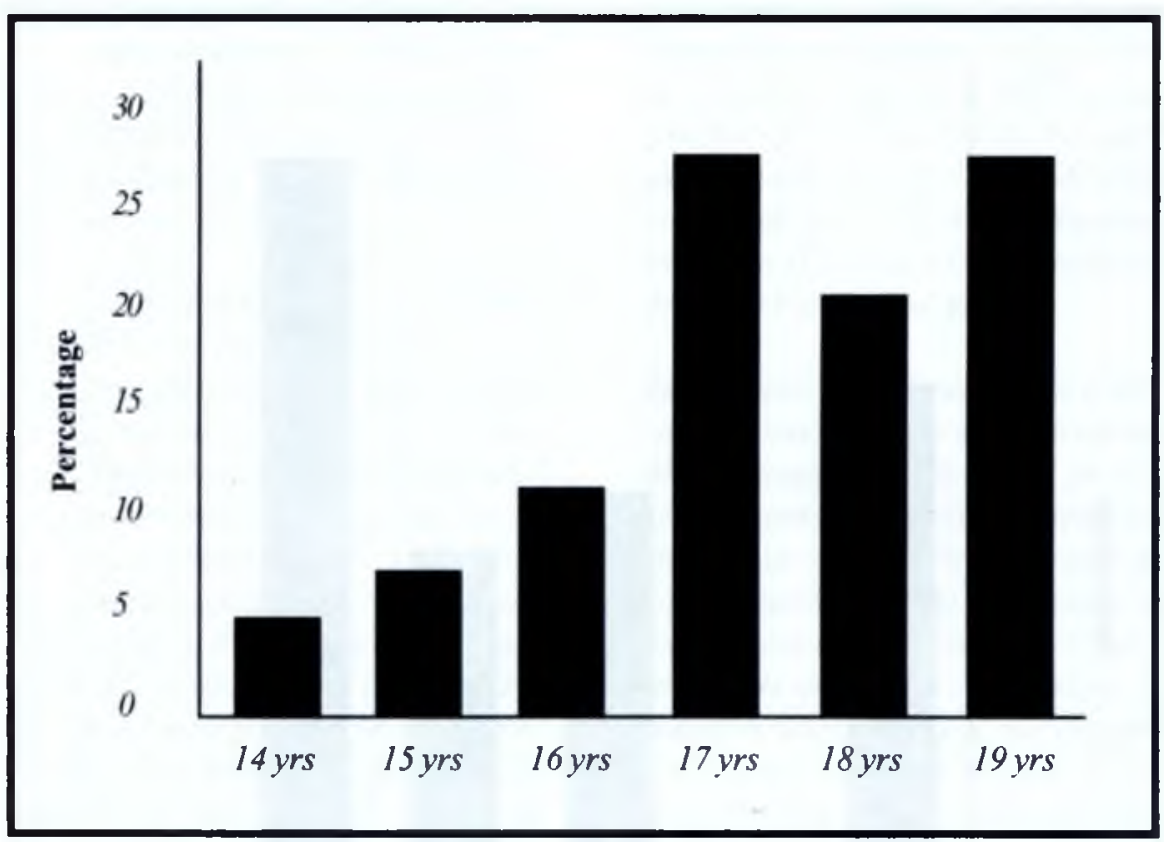

\section{Research results: analysis and discussions}

The results and discussion of the data analysis was guided by the components of the HBM.

\section{Modifying factors}

According to the HBM modifying factors such as age, marital status, educational level, parity and income can influence decisions to utilise ANC services.

\section{Figure 2: Marital status of the respondents $(n=80)$}

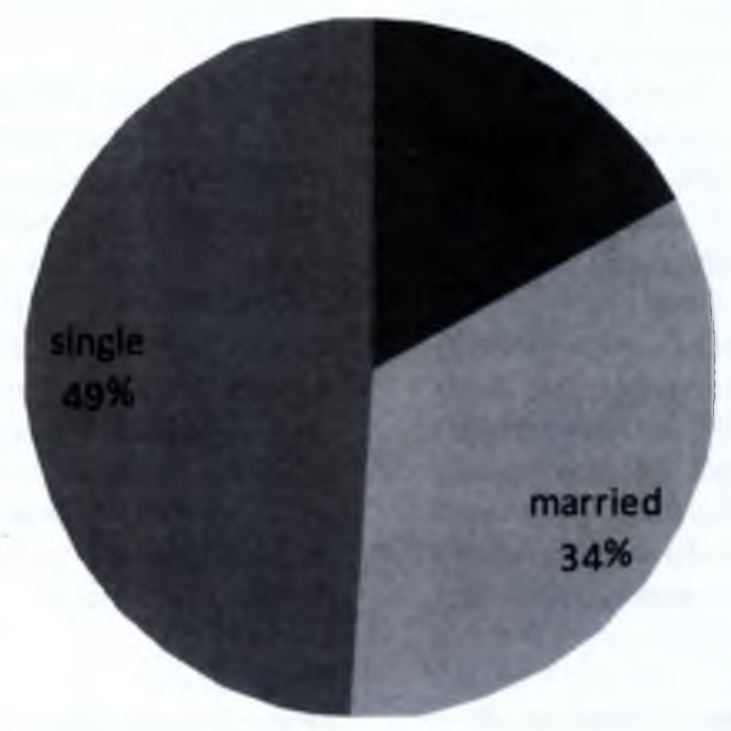




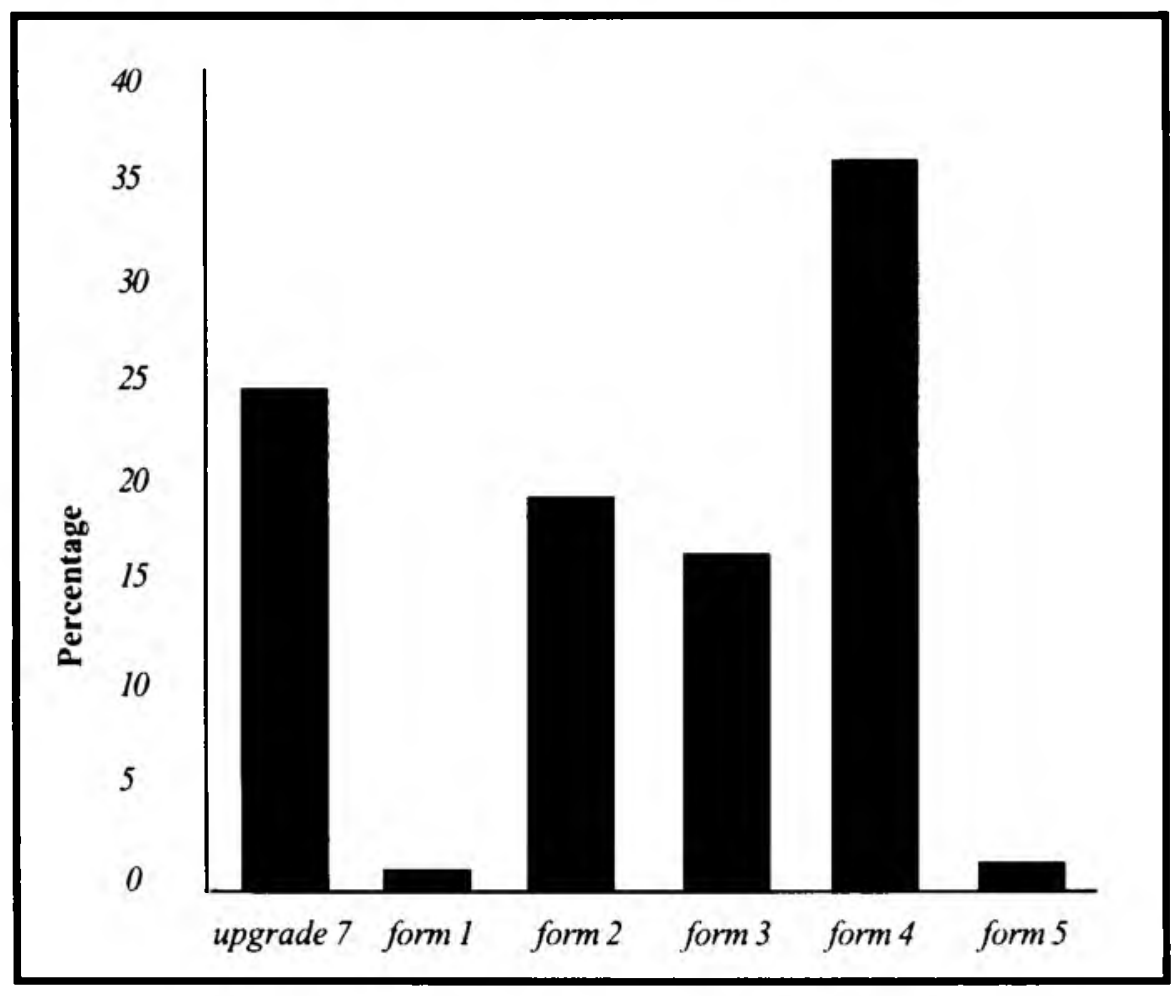

Marital status and residency

Of the adolescent mothers, 39 (48.8\%) were single, 27 (33.8\%) were married, while $14(17.5 \%)$ were cohabiting (see Figure 2). Thirty-six (45.0\%) lived with their parents, $32(40.0 \%)$ with spouses, $9(11.3 \%)$ with other members of the extended family and 3 (3.8\%) with friends.

\section{Educational level}

Pereira, Canavarro, Cardoso and Mendonça (2005:656) refer to a number of studies (Coley \& Chase-Lansdale 1998; Garrett \& Tidudl 1999; and Yamolskaya, Brown \& Greenbaum 2002) indicating that pregnant adolescents "have lower levels of education. lower educational aspirations and performance, and higher levels of school dropout". In this study all respondents were literate (Figure 3). The majority $(n=60 ; 75.0 \%)$ had acquired some secondary school education (Form 15), while a few had studied up to Grade $7(n=20 ; 25.0 \%)$, the last year at primary school in Zimbabwe. The major reason for leaving school was pregnancy $(n=22 ; 27.5 \%)$ and a lack of money to pay school fees or proceed with their studies $(n=22 ; 27.5 \%$ ).

\section{Employment status and sources of income}

Most respondents were unemployed $(n=70 ; 87.5 \%)$ and $10(12.5 \%)$ were em- ployed. Those employed were mainly general workers. Their spouses $(n=40$; $50 \%)$, parents $(n=30 ; 37.5 \%)$, self $(n=6$; $7.5 \%$ ) and other sources such as nongovernment organisations (NGOs) $(n=4 ; 5 \%)$ provided them with an income. More than half $(n=52 ; 65.0 \%)$ of their spouses were employed, 25 (31.2\%) were unemployed and the remaining $3(3.8 \%)$ spouses 'employment status was reportedly unknown. The job categories of spouses included skilled work ( $n=25 ; 31.2 \%)$, general work $(n=11 ; 13.7 \%)$, self-employment $(n=9 ; 11.3 \%)$ and professional work $(n=7 ; 8.8 \%)$.

These findings are supported by Cassata and Dallas (2005:72), who observed that unemployed, single and economically dependent adolescent mothers were unlikely to utilise $A N C$ services. However, $52(65.0 \%)$ of their spouses were employed. These adolescents could therefore get financial support from their employed spouses (Adamu \& Salihu, 2002:600; Perloff \& Jaffee, 1999:117), although these incomes might have been inadequate to pay for ANC services.

\section{Parity}

Of the 80 respondents, 69 (86.3\%) reportedly had their first pregnancies, while 11 (13.8\%) had been pregnant for the second time. Sixty-eight $(85.0 \%)$ respondents had one live baby, 9 (11.2\%) had two live children while 3 (3.8\%) had no live children due to stillbirths or neonatal deaths.

\section{Individual factors}

Respondents were asked in an openended question to mention at least three factors that would motivate them to utilise ANC services with their future pregnancies. The main factors mentioned were grouped into the following categories.

\section{- Adequate knowledge about ANC services and its benefits $(n=58 ; 72.5 \%)$ \\ - Accessible, acceptable and af- fordable ANC services $(n=62$; $77.5 \%)$ \\ - Favourable family and social support systems $(n=55 ; 68.8 \%)$. \\ - Quality services, satisfying the needs of adolescent mothers $(n=49 ; 61.3 \%)$ \\ - $\quad$ Unsure $(n=16 ; 20.0 \%)$.}

The respondents avoided initiating ANC because of their individual perceptions about ANC services, due to their limited knowledge of, and misconceptions about. ANC services, and their perceptions that poor quality $A N C$ services would not benefit them or their babies.

\section{Socio-cultural and economic factors}

According to the HBM, socio-economic factors are viewed as modifying factors that could influence the utilisation of ANC services. Reynolds et al (2006:6) reported that poor maternal outcomes were associated with sociocultural factors, restricting women's autonomy and supporting harmful traditional and/or religious practices. Maimbolwa, Ahmed, Divan and RansjoArvidson (2003:33) reported that adolescents were so scared of revealing their pregnancies; they risked their lives by seeking unsafe abortions.

Respondents were asked about the type of contraceptives they had used prior to their pregnancies. Most $(n=46$; $57.5 \%)$ indicated that they had used nothing, 17 (21.3\%) used male condoms, 9 (11.3\%) used pills, 4 (5.0\%) used injections while $4(5.0 \%)$ relied on breastfeeding (see Table 1). 
Table 1: Family Planning method $(n=80)$

\begin{tabular}{|l|l|l|}
\hline Method & $\mathbf{n}$ & $\%$ \\
\hline Pill & 9 & 11.3 \\
IUCD & 00 & 00 \\
Injection & 4 & 5.0 \\
Condom & 17 & 21.3 \\
Breastfeeding & 4 & 5.0 \\
Abstinence & 00 & 00 \\
Nothing & 46 & 57.5 \\
Total & 80 & 100 \\
\hline
\end{tabular}

Respondents indicated that they failed to use contraceptives correctly because of a lack of knowledge and problems in accessing family planning services $(n=40 ; 50.0 \%)$. Similar findings (Dahlback, Maimbolwa, Kasonka, Bergstrom \& Ransjo-Arvidson, 2007:670) were reported by other researchers. Mbambo, Ehlers and Monareng (2006:8) also reported that most South African adolescent mothers did not use contraceptives and knew little about contraceptives. Individual perceptions about contraceptives included fears of their parents' reactions should it be discovered that they used contraceptives (Ehlers, 2003:229).

Sixteen (20.0\%) respondents admitted defaulting. Ten (12.5\%) stated cultural and religious reasons while $5(6.2 \%)$ cited contraceptive method failures (see Table 2).

Not all adolescent pregnancies are unwanted. Bryant (2006:134) refers to a

Table 2: Reasons for stopping family planning $(n=80)$

Reasons for their non-utilisation of
ANC services during their last preg-
nancies (see Table 3), included fears of
disclosing their pregnancies to their
parents or schools ( $n=19 ; 23.8 \%$ ), they
were feeling well and their babies were
kicking ( $n=18 ; 22.5 \%$ ) and $16(20.0 \%$ )

Reasons for their non-utilisation of
ANC services during their last preg-
nancies (see Table 3), included fears of
disclosing their pregnancies to their
parents or schools ( $n=19 ; 23.8 \%)$, they
were feeling well and their babies were
kicking ( $n=18 ; 22.5 \%$ ) and $16(20.0 \%$ )

Reasons for their non-utilisation of
ANC services during their last preg-
nancies (see Table 3), included fears of
disclosing their pregnancies to their
parents or schools ( $n=19 ; 23.8 \%)$, they
were feeling well and their babies were
kicking ( $n=18 ; 22.5 \%$ ) and $16(20.0 \%$ )

Reasons for their non-utilisation of
ANC services during their last preg-
nancies (see Table 3), included fears of
disclosing their pregnancies to their
parents or schools ( $n=19 ; 23.8 \%)$, they
were feeling well and their babies were
kicking ( $n=18 ; 22.5 \%$ ) and $16(20.0 \%$ )

Reasons for their non-utilisation of
ANC services during their last preg-
nancies (see Table 3), included fears of
disclosing their pregnancies to their
parents or schools ( $n=19 ; 23.8 \%)$, they
were feeling well and their babies were
kicking ( $n=18 ; 22.5 \%$ ) and $16(20.0 \%$ )

Reasons for their non-utilisation of
ANC services during their last preg-
nancies (see Table 3), included fears of
disclosing their pregnancies to their
parents or schools ( $n=19 ; 23.8 \%)$, they
were feeling well and their babies were
kicking ( $n=18 ; 22.5 \%$ ) and $16(20.0 \%$ )

Reasons for their non-utilisation of
ANC services during their last preg-
nancies (see Table 3), included fears of
disclosing their pregnancies to their
parents or schools ( $n=19 ; 23.8 \%)$, they
were feeling well and their babies were
kicking ( $n=18 ; 22.5 \%$ ) and $16(20.0 \%$ ) lacked money to pay ANC fees.

For 69 (86.3\%) of the respondents this was the first pregnancy and thus they had not experienced previous pregnancy problems. Three respondents (3.8\%) had experienced problems with previous pregnancies, including neonatal deaths $(n=2 ; 2.5 \%)$, abortion $(n=1 ; 1.2 \%)$ and pre-eclampsia $(n=1 ; 1.2 \%)$. Out of the $11(12.5 \%)$ respondents who had been pregnant previously, 4 (5.0\%) had reportedly attended $A N C$ and 7 (8.8\%) delivered their babies without attending $A N C$. Reasons for not utilising ANC services during their previous pregnancies included that they were feeling well, religious factors, financial constraints and fears of disclosing their pregnancies to their parents. They preferred their pregnancies to be discovered when in labour: This preference of pregnant adolescents could influence their non-utilisation of ANC senices detrimentally with potentially hazardous effects for both mothers and babies.

Fourteen respondents (17.5\%) re-

\begin{tabular}{|l|l|l|}
\hline Reason & $\mathbf{n}$ & $\%$ \\
\hline Default & 16 & 20.0 \\
No reason & $(0)$ & $(0)$ \\
Lack of knowledge of family planning & 40 & 50.0 \\
Method failure & 5 & 6.3 \\
Wanted a baby & 9 & 11.3 \\
Cultural and religious reasons & 10 & 12.5 \\
Total & 80 & 100 \\
& & \\
\hline
\end{tabular}
ported limited knouledge about benefits of ANC, while $7(8.8 \%)$ were receiving services of traditional birth attendants (TBAs). Four $(5.0 \%) \mathrm{re}$ spondents did not attend ANC because they required documents (Zimbabwe national identity cards) to register for ANC while two (2.5\%) cited religious factors. If they had money, 29 (36.2\%) respondents indicated they would book for ANC while 29 (36.2\%) were unsure, only 21 (26.2\%) would definitely book for ANC if they had money. while one $(1.2 \%)$ would definitely not do so even if she had money.

Respondents chose to deliver at health centres, even if they did not attend ANC because more than half $(n=42$; $52.5 \%$ ) wanted safe deliveries by skilled attendants, while obstetric complications forced $35(43.8 \%)$ respondents to seek hospital care. Three (3.8\%) respondents delivered their babies in hospitals/clinics because they wanted birth record notification letters to $o b$ tain their babies 'birth certificates without hassles from Zimbabawe's Ministry of Home Affairs.

A number ( $n=29 ; 36.3 \%)$ indicated that they were unaffected by complications, whereas $21(26.3 \%)$ respondents agreed that some complications could have been prevented if they had attended ANC.

Factors contributing to non-utilisation of $A N C$ services were cited as limited knowledge about ANC benefits ( $n=25$; $31.3 \%)$, financial constraints $(n=17$; $21.3 \%)$, fears of disclosing their pregnancies to their parents $12(15.0 \%)$, unplanned pregnancies $(n=11 ; 13.8 \%)$ and the desire to terminate the pregnancy $(n=2 ; 2.5 \%)$

\section{Knowledge about ANC}

Knowledge was identified as the major structural variable that could affect adolescents' utilisation of ANC services. Most respondents $(n=78 ; 97.5 \%)$ agreed with the statement that $A N C$ provides increased knowledge about reproductive health, while $2(2.5 \%)$ disagreed with this statement. Almost all respondents ( $n=77 ; 96.3 \%$ ) agreed that early ANC booking enhances the wellbeing of the mother and the baby and that ANC provides opportunities to detect and manage complications related to pregnancy and child birth; $A N C$ provides learning opportunities enabling one to identify potential complications and seek help. Only 3 (3.7\%) respondents disagreed with the preceding statements. 
Table 3: Reasons for not attending ANC with last pregnancies $(n=80)$

\begin{tabular}{|l|l|l|}
\hline Reason & $\mathbf{n}$ & $\%$ \\
\hline Fear of disclosing the pregnancy & 19 & 23.8 \\
Feeling well and the baby was kicking & 18 & 22.5 \\
No money to register for ANC & 16 & 20 \\
Limited knowledge about ANC and its benefits & 14 & 17.5 \\
No required documents to register for ANC & 4 & 5.0 \\
Attended ANC with TBAs & 7 & 8.8 \\
Religious factors & 2 & 2.5 \\
Total & 80 & 100 \\
\hline
\end{tabular}

All most all respondents $(n=77 ; 96.3 \%)$ indicated that $A N C$ does provide opportunities to learn about sexually transmitted infections (STIs), HIV and prevention of mother-to-child transmission (PMTCT) of HIV/AIDS, while three (3.8\%) disagreed.

These adolescent mothers lacked knowledge about ANC and agreed that adequate knowledge about ANC's benefits could motivate them to utilise $A N C$ services in future, similar to Matua's (2004:35) findings.

\section{Perceived benefits and barriers}

$A$ significant correlation $(p=0.000$ $p<0.05)$ between awareness of perceived ANC benefits and potential future utilisation of ANC services was found. Respondents' awareness of ANC benefits increases their intentions of utilising $A N C$ services with their future pregnancies. Adequate knowledge of ANC services in Bulawayo would motivate 44 (55.0\%) respondents to utilise $A N C$ services in future; 38 (47.5\%) definitely perceived accessible and acceptable ANC as benefits; 66 (82.5\%) said free $A N C$ services would benefit them, while $14(17.5 \%)$ felt that free $A N C$ services would not be beneficial to them. Only two (2.5\%) respondents disagreed with the statement that quality ANC services would motivate them to utilise ANC services, while only one (1.3\%) disagreed that ANC services would meet adolescents' needs, would motivate her to use ANC services in future.

Adolescents are, however, likely to utilise ANC services if they perceive at- tending ANC would be beneficial for reducing the incidence of complications or preventing them, while identifying and resolving any barriers to reproductive health (Biko 2006:55).

There was a significant correlation $(p=0.000 ; p<0.05)$ between identlfied barriers and respondents' future planned non-utilisation of ANC services in Bulawayo. The most significant barriers were high ANC fees $(n=69$; $86.3 \%)$, unfriendly attitudes of health workers ( $n=51 ; 63.8 \%$ ), poor family and social support systems ( $n=74,92.6 \%)$, fear of testing for HIV $(n=73 ; 91.3 \%)$, positive HIV status $(n=75 ; 93.8 \%)$ and limited decision making powers $(n=67$; 83.8), as most respondents were financially dependent on their parents, husbands or partners

\section{Conclusion}

Factors influencing adolescent mothers' non-utilisation of ANC services included socio demographic factors, individual perceptions about ANC, limited knowledge about $A N C$, economic challenges, policy-related and structural barriers. A policy-related barrier was requiring national Zimbabwean identity cards of themselves or their spouses in order to register for ANC. Pregnant adolescents, younger than 18 or unmarried or whose spouses did not have the required identity cards, could not access ANC services in Bulawayo. Some adolescents reportedly delivered their babies at health centres in order to obtain birth record letters, used to get their children's birth certificates.

However, these adolescent mothers knew that delivering their babies with the assistance of skilled attendance by nurses/midwives and/or doctors, could enhance the health of the mothers and their babies, help to secure documents to facilitate the acquisition of their children's birth certificates and address obstetric complications.

Adolescent mothers did not use ANC services if they had negative perceptions about the quality of these services and/or the service providers' attitudes, if they lacked knowledge about $A N C$ 's benefits and fears of getting tested for HIV and of learning about one's positive HIV status.

\section{Limitations}

Generalisation of the results of this study is subject to the following limitations:

non-probability sampling methods were used, which prevent generalisation of the results to the entire population. However, all the study health centres were included in the sample meaning that the views of the adolescents in Bulawayo could have been represented. The views of the unbooked adolescents who delivered at home were not represented in this study because they could not be accessed. The use of research assistants could have created variances although they were trained and coached until they had mastered questioning and recording skills.

The study utilised one theoretical framework (HBM) which accommodated all the key variables likely to influence adolescent mothers' utilisation of ANC services. However, different study findings might have emerged if a multi-theory approach had been used.

\section{Recommendations}

Based on the findings of the study the following recommendations were made:

- Revision and strengthening of strategies reaching out to adolescents who might be affected by bio-psychosocial and economic factors, including knowledge that influences their access to ANC and family planning services. $A N C$ programmes should enhance reaching those adolescents who are still at school.

- $\quad$ Offering free $A N C$ services 
should receive serious attention in Zimbabwe since the pregnant adolescents might be unable to pay the ANC fees.

- Regular audits should be done of adolescents' reproductive health programmes ensuring that they are adolescent friendly.

- $\quad$ Addressing those barriers and restrictive policies that interfere with accessibility of $A N C$ services, such as abandoning the requirement of producing a Zimbabwean identity document prior to getting registered for ANC services

\section{References}

ADAMU, YM \& SALIHU, HM 2002. Barriers to the use of antenatal and obstetric services in rural Nigeria. Journal of Obstetrics and Gunaecology: 22(6):600-603

ARETAKIS, DA 2004. Teen pregnancy in community and public health nursing edited by $M$. Stanhope and J Lancaster. Mosby. hitp:/l evolve.elsevier.com/stanope

BIKO, L 2006. Adolescent reproduction and contraception. Obstetrics and Gunaecologv Forum. 16:55-57

BRYANT, KD 2006. Update on adolescent pregnancy in the Black community The ABNF Journal. Fall 133-136.

CASSATA, L \& DALLAS, C 2005. Nurses' attitudes and child bearing adolescents: bridging the cultural chasm. ABNF Journal 2005:71-76.

CITY OF BULAWAYO 2005. Annual report 2004. Bulawayo: Health Services Department.

DAHLBACK, E; MAIMBOLWA, M; KASONKA, L; BERGSTROM, S \& RANSJO-ARVIDSON 2007. Unsafe induced abortions among adolescent girls in Lusaka. Health Care for Women International. 28:654-676.

EBEIGBF, PN \& GHARORO EP 2007. Obstetric complications, intervention rates and materno-fetal outcomes in teenage nullipara in Benin city, Nigeria. Tropical Doctor 37(2):79-83.

EHLERS, VJ 2003. Adolescent moth- ers' utilization of contraceptive services in South Africa. International Nursing Review. 50:229-241.

EHLERS, VJ; MAJA, T; SELLERS, E \& GOLOLO, M 2000. Adolescent mothers' utilization of reproductive health services in the Gauteng Province of South Africa. Curationis. 23(3):43-51

FORD,K; WEGI ICKI, L; KERSHAW, T; SCHRAM, C; HOYER, JP \& JACOBSON, ML 2002. Effects of prenatal care intervention for adolescent mothers on birth weight, repeat pregnancy and educational outcomes at one year postpartum. Journal of Perinatal Education. II(I):35-38.

GROBLER, C; BOTMA, Y; JACOBS, AC \& NEL, M 2007. Beliefs of grade six learners ' regarding adolescent pregnancy and sex. Curationis. 30(1):32-40.

LESLIE, KM; FINDLAY, SM; FRAPPIER, JY; GOLDBERG, E; PINZON, J; SANKARAN, K \& TADDEO, D 2006. Adolescent pregnancy. Paediatric \& Child Health. 11(4):243-246.

LOTO, OM; EZECHI, OC; KALU, BKE; LOTO, AB; EZECHI, LO \& OGUNNIYI, SO 2004. Poor obstetric performance of teenagers: is it age-or quality of care related? Journal of $\mathrm{Ob}$ stetrics and Gvnecologv. 24(4):395-398.

MAIMBOLWAM;AHMED,Y;DVAN V \& RANSJO-ARVIDSON, A 2003. Safe motherhood perspectives and social support for primigravidae women in Lusaka, Zambia. Social Science \& Medicine. 58(11):29-34.

MATUA, AG 2004. Determinants of maternal choices for place of delivery in Ayivu County, Uganda. Africa Journal of Nursing and Midwifen: $6(1): 33$ 38.

MBAMBO, AN; EHLERS, VJ \& MONARENG, LV 2006. Factors influencing adolescent mothers ' non utilisation of contraceptives in the Mkhondo area of South Africa. Health South Africa Gesondheid. 11:1-18.

MINISTRY OF HEALTH ANDCHII .D WELFARE 2000. Zimbahue's goal-oriented ANC protocol. Harare: Government Printer.
MINISTRY OF HEALTH AND CHILD WELFARE 2005. $A N C$ and delivery registers 2004-2005. Bulawayo: Health Information Department.

MINISTRY OF HEALTH AND CHILD WELFARE 2007. Zimbabwe maternal and neonatal health road map. 2007-2015. Harare: Government Printer.

MOHCW - SeE MINISTRY OF HEALTH AND CHILD WELFARE

MOSBY NURSE'S POCKET DICTIONARY 2005. $33^{\text {rd }}$ edition. Edingburgh: Elsevier Mosby.

MUGWENL, E; EHLERS, VJ \& ROOS, JH 2008. Factors contributing to low institutional deliveries in the Marondera district of Zimbabwe. Curationis. 32(2):5-13.

OMOLOLA, OI; BABATUNDE, AO; BABALOLA, AA \& VICTORIA, AT 2004. Analysis of parents 'and adolescents' concerns and prescriptions for prevention and management of teenage pregnancy. Africa Journal of Nursing and Midwifery. $6(1): 25-32$.

PEREIRA, AIF; CANAVARRO, MC; CARDOSA, MF \& MENDONÇA, D 2005. Relational factors of vulnerability and protection for adolescent pregnancy: a cross-sectional comparative study of Portuguese pregnant and nonpregnant adolescents of low socioeconomic status. Adolescence. 40(159):655-671

PERLOFF, JD \& JAFFEE KD 1999. Late entry into prenatal care: the neighbourhood context. Social Work. 44(2): $116-128$

POLIT, DF \& BECK, CT 2004. Nursing research: principles and methods. $7^{\text {ih }}$ Edition. Philadelphia: JB Lippincott.

RECAPP. 2005. Theories and approaches. Health Belief Model. http:/ /www.ert.org/recapp/theories/hbm/. (Accessed on 11 March 2005).

REYNOLDS, HW; WONG, EL \& TUCKER, H 2006. Adolescents' use of maternal and child health senices in developing countries. International Family Planning Perspectives. 32(1):6-16. 